SUPPORTING INFORMATION

\title{
Enhanced Productivity of a Supported Olefin Trimerization Catalyst
}

\author{
Aaron Sattler, Dinesh C. Aluthge, Jay R. Winkler, Jay A. Labinger,* and John E. Bercaw,* \\ Arnold and Mabel Beckman Laboratories of Chemical Synthesis, \\ California Institute of Technology, \\ Pasadena, California, 91125, USA.
}

Received $x x x x \times x, 2015$

\section{Corresponding Author}

jal@caltech.edu; bercaw@caltech.edu 


\section{General Considerations}

All manipulations were performed using glovebox, high-vacuum, and/or Schlenk techniques under a nitrogen or argon atmosphere unless otherwise specified. ${ }^{1}$ Solvents were purified and degassed by using standard procedures. X-band EPR spectra were acquired either at room temperature or at $77 \mathrm{~K}$ on a Bruker EMX spectrometer. 1-Pentene, 1-hexene, and 1-decene were dried over molecular sieves (3 Å) for at least two days, then filtered through activated alumina and stored over molecular sieves ( $3 \AA$ ) prior to use. $\mathrm{MAO}$ (30\% in toluene) was purchased from Albemarle Corporation and stored at $-30{ }^{\circ} \mathrm{C}$ inside a nitrogen glovebox freezer. Silica (MS-3030) was purchased from PQ Corporation and heated at $300{ }^{\circ} \mathrm{C}$ under vacuum for $5 \mathrm{~h}$ and then stored in a nitrogen glovebox. ( $\mathrm{FI}$ ) $\mathrm{TiCl}_{3}$ was prepared by the literature method. ${ }^{2}$

\section{Gas Chromatography Analysis}

Gas chromatography (GC) was performed on an Agilent $6890 \mathrm{~N}$ instrument using a DB-1 capillary column (10 m length, $0.10 \mathrm{~mm}$ diameter, $0.40 \mu \mathrm{m}$ film) and a flame ionization detector. Response factors were previously calculated, ${ }^{3}$ and the same analysis was performed as in previous studies. ${ }^{2 b}$ Gas chromatography/mass spectrometry (GC-MS) was performed on an Agilent 6890N instrument using a HP-5MS column (30 m length, $0.25 \mathrm{~mm}$ diameter, $0.50 \mu \mathrm{m}$ film) and an Agilent 5973N mass-selective EI detector.

\section{Synthesis of $\mathrm{s}(\mathrm{FI}) \mathrm{Ti}$}

A suspension of dry MS3030 silica ( $2 \mathrm{~g})$ in toluene $(30 \mathrm{~mL})$ was treated with MAO (30\% in toluene, 3.5 $\mathrm{mL}$ ). The mixture was stirred at room temperature for 2 hours, and then treated with a solution of (FI) $\mathrm{TiCl}_{3}(33 \mathrm{mg}, 0.055 \mathrm{mmol})$ in toluene $(15 \mathrm{~mL})$. The mixture was stirred at room temperature for 1 hours, changing color from red to yellow, after which the volatile components were removed in vacuo at $30^{\circ} \mathrm{C}$, giving a dry yellow powder $(3.046 \mathrm{~g}, 0.0179 \mathrm{mmol} \mathrm{Ti} / \mathrm{g}$ of silica; Al:Ti ratio is $300: 1)$. 


\section{Kinetics Simulations}

Simulations employed the three steps (initiation, trimerization, decomposition) shown below, and were solved using an ordinary differential equation (ODE) solver in MATLAB. The actual dependence of the various steps on ethylene concentration is not known with any certainty; but since the latter was held constant at $100 \mathrm{mM}$ for all experiments, we have treated all the rate constants, $k_{i j} k_{t}$ and $k_{d}$, as pseudofirst order.

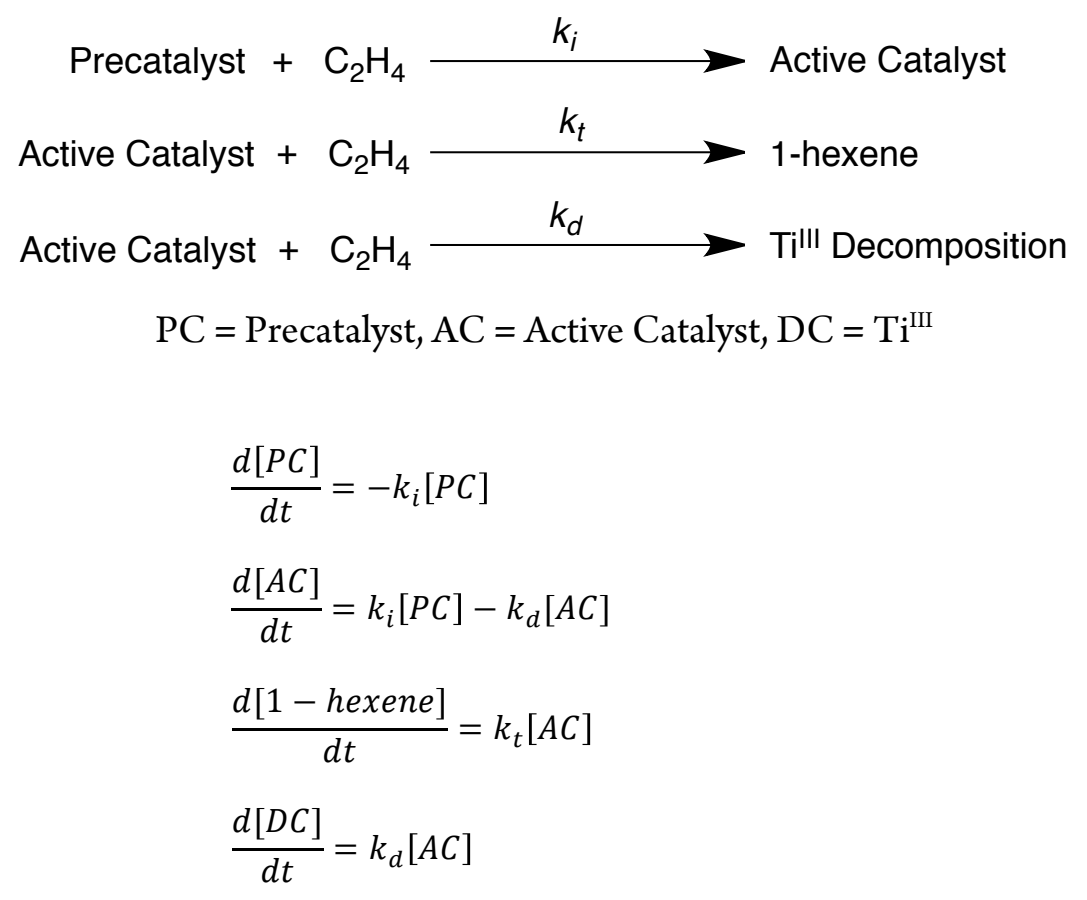

\section{Catalytic Trimerization of Ethylene with s(FI)Ti}

In a typical experiment, $\mathrm{s}(\mathrm{FI}) \mathrm{Ti}(50-200 \mathrm{mg}, 0.9-3.6 \mu \mathrm{mol})$ was added to a $100 \mathrm{~mL}$ round bottom flask with a magnetic stirbar and was treated with toluene $(10-15 \mathrm{~mL})$. (Experiments with other solvents - pentane, benzene, chlorobenzene and difluorobenzene — all gave poorer results and were not pursued.) The flask was adapted with a $180^{\circ}$ joint and sealed with a teflon valve. The flask was connected to a high vacuum line, and the suspension was frozen, degassed, and allowed to warm to room temperature. The flask was then charged with $\mathrm{C}_{2} \mathrm{H}_{4}(1 \mathrm{~atm})$ and stirred for ca. 1 day under constant $\mathrm{C}_{2} \mathrm{H}_{4}$ pressure $(1 \mathrm{~atm})$ at room temperature. After this period, the volume of the solution had increased 
significantly (ca. $5-10 \mathrm{~mL}$ ), with formation of small amounts of polymer. Adamantane (ca. $50 \mathrm{mg}$ ) was then added as an internal integration standard, and the mixture was treated with acetone (ca. $20 \mathrm{~mL}$ ) and methanol (ca. $20 \mathrm{~mL}$ ) to help precipitate any polyethylene. The solids were allowed to settle, and an aliquot of the supernatant was filtered through a plug of silica gel and analyzed by GC to determine the yields of 1-hexene, $\mathrm{C}_{10}$ and $\mathrm{C}_{14}$ olefins; TONs of ca. $1.0 \times 10^{5} \mathrm{mmol}$ olefin oligomerized $/ \mathrm{mmol} \mathrm{Ti}$ were found. The polymer/silica solids were isolated by filtration, dried at $70{ }^{\circ} \mathrm{C}$, and then in vacuo, and weighed to obtain polymer yields.

A similar experimental setup was used for the kinetic monitoring of catalysis, except that a two neck round bottom flask was used, with the second port sealed using a suba-seal septum, and adamantane was added at the beginning of the experiment. Aliquots were taken at chosen times using a micro syringe, and analyzed by GC. Results are shown in Figure 3 of the main text.

\section{Catalytic Trimerization of $\alpha$-Olefin}

In a typical experiment, $\mathrm{s}(\mathrm{FI}) \mathrm{Ti}(50-200 \mathrm{mg}, 0.9-3.6 \mu \mathrm{mol})$ was added to a $20 \mathrm{~mL}$ glass vial with a magnetic stirbar and was treated with $\alpha$-olefin $(5-10 \mathrm{~mL}$ of 1-pentene, 1-hexene or 1-decene). The vial was capped, and the suspension was stirred for $1-2$ days. Adamantane (ca. $25 \mathrm{mg}$ ) was then added as an internal integration standard, and the mixture was treated with acetone (ca. $5 \mathrm{~mL}$ ) and methanol (ca. $5 \mathrm{~mL}$ ) to help precipitate any poly-1-olefin. The solids were allowed to settle, and an aliquot of the supernatant was filtered through a plug of silica gel and analyzed by GC. The polymer/silica solids were isolated by filtration, dried at $70{ }^{\circ} \mathrm{C}$, and then in vacuo, and weighed to obtain yields. GC analysis demonstrated the catalytic production of $\mathrm{C}_{3 \mathrm{n}}$ olefins $(\mathrm{n}=$ carbon number of $\alpha$-olefin), with only trace amounts of dimers or tetramers. Trimerization TONs of ca. $6.0 \times 10^{3} \mathrm{mmol}$ olefin oligomerized $/ \mathrm{mmol}$ Ti were obtained.

A similar experimental setup was used for the kinetic monitoring of 1-hexene trimerization, except that adamantane was added initially. Aliquots were taken at desired times using a micro syringe, and analyzed by GC. Results are shown in Figure S1, and the parameters obtained from modeling in Table S1. The concentration of 1 -hexene, which is in large excess, does not change appreciably over the course 
of catalysis, so that pseudo-first order kinetics apply. Simulated parameters, obtained in the same manner as those for ethylene trimerization, are shown in Table S1.

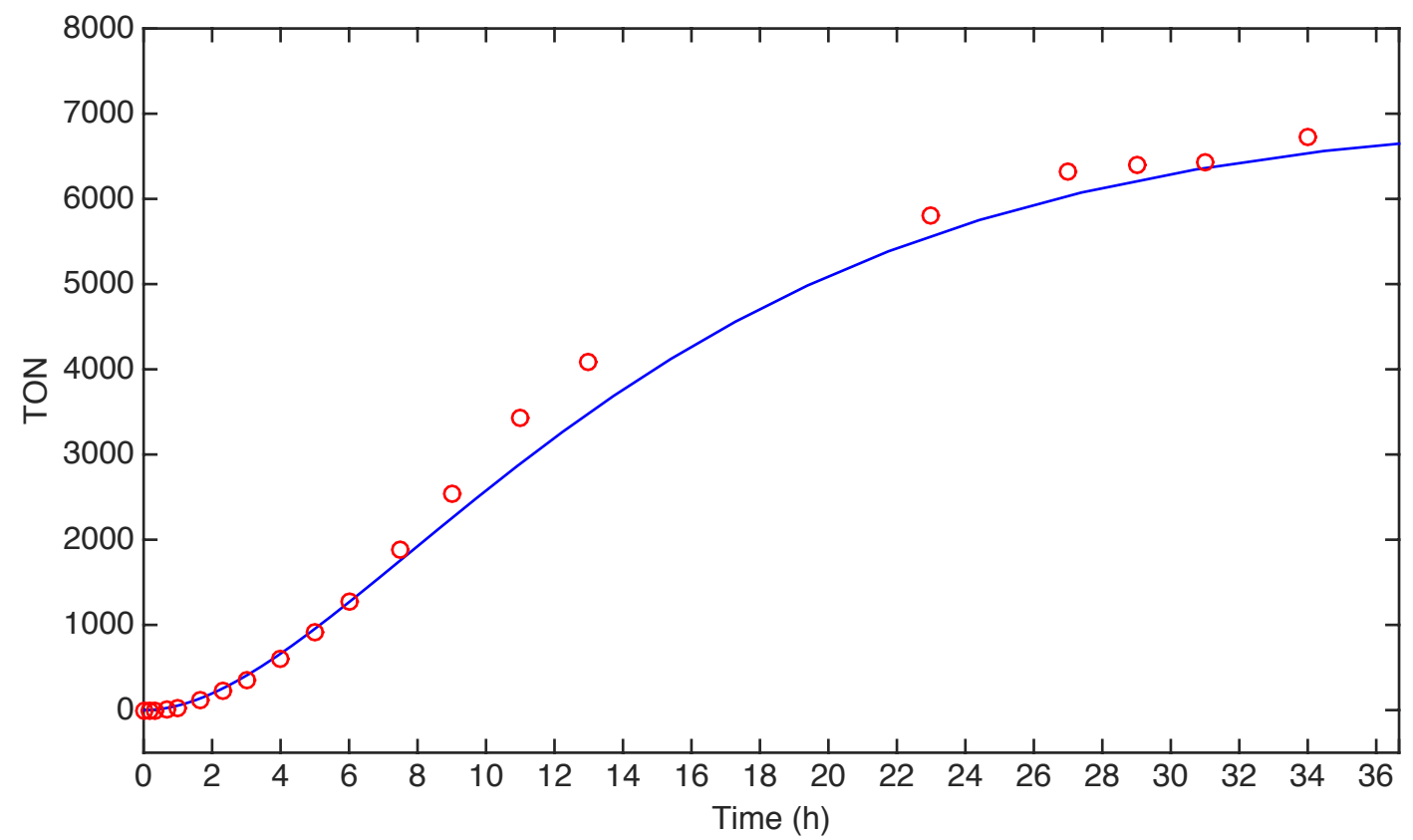

Figure S1. TON vs. time for 1-hexene trimerization by s(FI)Ti. Red circles are experimental values; blue line is simulated values based on parameters in Table $S 1$.

Table S1. Simulated kinetics parameters for 1-hexene trimerization by s(FI) $\mathrm{Ti}^{{ }^{a}}$

\begin{tabular}{lccc}
\hline 1-hexene trimerization & $k_{i}$ & $k_{t}$ & $k_{d}$ \\
\hline $\mathrm{s}(\mathrm{FI}) \mathrm{Ti}$ & $3.3 \times 10^{-5}$ & $8.8 \times 10^{-2}$ & $3.9 \times 10^{-5}$ \\
\hline
\end{tabular}

${ }^{a}$ Rate constants are all pseudo-first order, with units $\mathrm{s}^{-1}$

\section{Analysis of Silanol Content}

In a typical experiment, MS-3030 (ca. $100 \mathrm{mg}$ ) was added to a two-neck flask, and treated with toluene (ca. $5 \mathrm{~mL}$ ). In a separate flask, $\mathrm{AlMe}_{3}(\mathrm{ca} .0 .1 \mathrm{~mL})$ in toluene $(\mathrm{ca} .10 \mathrm{~mL}$ ) was added, sealed with a Teflon valve, and connected to the two-neck flask via a 24/40 joint. The second port of the two-neck flask was closed with a Teflon valve; the system was connected to a high vacuum line, and degassed by 
three freeze-pumped-thawed cycles. The $\mathrm{AlMe}_{3} /$ toluene solution was then added to the silica, and the amount of evolved gas was determined by Toepler pump analysis. 


\section{References:}

(1) (a) McNally, J. P.; Leong, V. S.; Cooper, N. J. in Experimental Organometallic Chemistry, Wayda, A. L.; Darensbourg, M. Y., Eds.; American Chemical Society: Washington, DC, 1987; Chapter 2, pp 6-23.

(b) Burger, B. J.; Bercaw, J. E. in Experimental Organometallic Chemistry; Wayda, A. L.;

Darensbourg, M. Y., Eds.; American Chemical Society: Washington, DC, 1987; Chapter 4, pp 79-98.

(c) Shriver, D. F.; Drezdzon, M. A.; The Manipulation of Air-Sensitive Compounds, $2^{\text {nd }}$ Edition; Wiley-Interscience: New York, 1986.

(2) (a) Suzuki, Y.; Kinoshita, S.; Shibahara, A.; Ishii, S.; Kawamura, K.; Inoue, Y.; Fujita, T. Organometallics 2010, 29, 2394-2396.

(b) Sattler, A.; Labinger, J. A.; Bercaw, J. E. Organometallics 2013, 32, 6899-6902.

(3) Leitch, D. C.; Lam, Y. C.; Labinger, J. A.; Bercaw, J. E. J. Am. Chem. Soc. 2013, 135, 1030210305. 